\title{
A INCESSANTE TRAVESSIA DOS TEMPOS E A RENOVAÇÃO DOS PARADIGMAS: A FAMÍlIA, SEU STATUS E SEU ENQUADRAMENTO NA PÓS-MODERNIDADE*
}

\author{
THE UNCEASING CROSSING OF TIMES AND PARADIGMS RENOVATION: FAMILY, ITS STATUS
}

AND FRAMING IN POST-MODERNITY

\section{Giselda Maria Fernandes Novaes Hironaka“}

\begin{abstract}
Resumo:
A evolução no tempo e a renovação dos paradigmas da família e o status do seu enquadramento na pós-modernidade, juntos à independência econômica da mulher em uma sociedade pós-moralista.
\end{abstract}

Palavras-chave: Família. Independência econômica. Sociedade pós-moralista. Desafios da vivência contemporânea no Brasil.

\begin{abstract}
:
The evolution along the time and paradigms renovation of family and the status of its framing in post-modernity, joined tothe economic independence of women in a post-moralist society.
\end{abstract}

Keywords: Family. Economic independence. Post-moralist society. Challenges of contemporary live in Brazil.

1. Um primeiro olhar por sobre o assunto

Desde o final do século anterior e durante, principalmente, estes anos que marcam o início do novo século, muito se falou em pós-modernidade e muito se discutiu acerca do retrato e perfil da família, enquanto instituição perenemente inserida no contexto - histórico, político, econômico, social - da civilização humana.

A produção que tem derivado desta formidável vertente de consagração do ancestral fenômeno de ajuntamento de pessoas à volta de um núcleo internalizado pelo matiz familiar é inegavelmente próspera, rica, intrigante e instigante. As formulações reflexivas que são possiveis de serem desenvolvidas e realizadas são inúmeras e

Esta matéria teve seu conteúdo inteirado na palestra de encerramento proferida no Congresso Internacional de Direito de Familia. promovido pelo Instituto Brasileiro de Direito de Familia - IBDFAM, na cidade de Brasilia, entre os dias 15 e 17 de novembro de 2006.

.. Doutora e Livre Docente em Direito pela Faculdade de Direito da Universidade de São Paulo. Professora Associada ao Departamento de Direito Civil da Faculdade de Direito da Universidade de São Paulo. Diretora Nacional para a Região Sudeste, do Instituto Brasileiro de Direito de Família - IBDFAM. ExProcuradora Federal. 
extremamente coerentes com tudo aquilo que se vê hoje, como a ustampa do núcleo da familia contemporànea.

Esta família atual não é melhor e nem é pior que a família do passado. mas certamente é muito diferente dos modelos familiais antecedentes, das estruturas de poder e de afeto que habitaram, construíram e modelaram os arquétipos anteriores a este que hoje conhecemos.

E é natural que assim seja. pois como num rio, as pedras que se esparramam pelo seu leito são distintas, se comparadas as mais próximas de sua origem ou nascente com aquelas que já estão mais próximas de sua vertente para o mar, de seu lugar de desaguar, enfim. As primeiras, mais cheias de arestas e mais rústicas são distintas destas últimas, mais roliças e menos agressivas que aquelas. Ambas são extraordinariamente belas, com valor próprio, com distinção intrínseca, com finalidade e papéis muito claros. Mas são distintas, pois a água do rio, de tanto passar, modifica a forma e modela-lhes o perfil.

Modelos de família, ancestrais. feudais, modernas e pós-modernas - para deixar reduzido, em poucas variações, o percurso intenso - se sucederam e a foto sohre a lareira foi se alterando com a mudança dos costumes, com a conversão ou inversão dos valores, com a introdução de novos comportamentos e de novos princípios, com o abandono de matrizes em desuso, e assim por diante. Por meio desta simbologia (da qual também me utilizo, agora) de mostrar a família por meio das fotos de um velho álbum, é de curiosa e real beleza a descrição que faz Luiz Edson Fachin em trabalho recentemente publicado.' O "símbolo" adotado mostra as mudanças e as nuanças da família de antes e da família de agora, quer pelas posturas na foto, quer pela indumentária utilizada pelas pessoas, quer pelo jogo cênico preparado para o registro eterno. Mudam e colorem-se as fotos: muda e revigora-se a família.

$\mathrm{A}$ independência econômica da mulher a faz erguer-se. na foto, sair de trás do patriarca, levantar os olhos confiantes de quem. ao lado de seu parceiro de vida, organiza e administra a estrutura familiar. Quanto aos filhos. seu papel também deixa de ser secundário e eles assumem boa elevação econômica na ordem familiar. assim como se destacam mais pelas suas qualidades próprias, seu preparo intelectual e sua crescente capacidade de decisão. O divórcio, o controle da natalidade, a concepção assistida, a reciprocidade alimentar são valores novos que passam a permear o tecido familiar, para torná-lo mais arejado, mais receptivo, mais maleável, mais adaptável às concepçôes atuais da humanidade e da vida dos humanos. A fidelidade, como valor que não se

FACHIN, Luiz Edson. Sobre os desafios e perspectivas da familia. seus projetos e seus direitos, no repensar do Direito Civil. Arte Juridica. Curitiba, v. 3, n. 1, p. 39-41, 2006. 
desprendia da virtude e da abnegação no anterior tempo, hoje se descortina como a aspiração individualista do amor autêntico, não-eivado de mentira ou de mediocridade, como descreve Gilles Lipovetsky em A sociedade pós-moralista: o crepúsculo do dever e a ética indolor dos tempos democráticos. ${ }^{2}$ Mas, acima de tudo, espalha-se a idéia de afetividade, como o grande parâmetro modificador das relações familiais, estando a querer demonstrar que o verdadeiro elo entre as pessoas envolvidas nessas relações. nesse núcleo, nesse tecido, consubstancia-se no afeto.

Não houve momento como esse, antes, seguramente. Não houve momento de reformulação das estruturas da família, através dos tempos, que tivesse dado o salto qualitativo em direção às emoções (performance maximamente otimizada do ser humano), sem ter que passar -- obrigatória ou exclusivamente - pelas veredas de antes, quais sejam, o prumo político, a revisão social e/ou o planejamento econômico. Dito de outra forma: nem só de arquétipos da modernidade vive a instituição da família, nos dias atuais; outras causas concorrem, ao lado daqueles, para apresentar a contextualidade que se impregna de mudanças e rupturas e que se tem considerado ser a pós-modernidade.

O historiador, o filósofo e, com eles, o jurista, passam a ter a visão cada vez mais aclarada do novo cenário, dos novos personagens, do novo script, sob o sugestivo título "família na pós-modernidade" Do que se trata, enfim? Como se processa este fenômeno, esta mudança, esta ruptura? Há mudanças sem ruptura? A reconfiguração das instituições se dá de modo abrupto? Quando é que passamos a compreender o momento novo, a conclamada "pós-modernidade"? Em que medida o tempo novo recepciona ou afasta o viés positivista de análise das relações familiais? Estas são as perguntas que pairam e solicitam respostas, ou esclarecimentos, ao menos.

Neste estudo, não se pretende oferecer as respostas (isso seria impossível, por certo), mas se pretende, ao menos, descortinar alguns esclarecimentos, ou melhor que isso, chamar à reflexão alguns pontos, algumas conjugações, certos conflitos e outras interações. Reflexões assim têm sido cada vez mais reclamadas exatamente por conta dos desafios da vivência contemporânea do Direito, dos quais resulta sempre esta certeza de que a dimensão das relações humanas e jurídicas, hoje, bem difere e se contrasta com a dimensão dos mesmos planos, em tempo imediatamente anterior. Não se trata, advirta-se desde logo, de apenas uma nova moda por meio da qual se inventa como se lançar o olhar por sobre os mesmos fenômenos, ou instituições, ou situações de antes. Mas trata-se, diferentemente, de atender à urgência - que resulta da prática da vida dos

LIPOVETSKY, Gilles. A sociedade pós-moralista: o crepúsculo do dever i a ética indolor dos tempos democráticos. Tradução Armando Braio Ara. Barueri (SP): Manole, 2005. p. 47. 
homens modificada pelos novos ares - de se construir um perfil distinto de análise e apreciação das conseqüências que o estar-no-mundo faz acontecer.

Mudam os homens. Mudam seus agrupamentos sociais. Mudam as instituições. Mudam os institutos jurídicos. Muda a família. Mudam as relações familiais, não para serem outras, mas para desempenharem novos e distintos papéis. Constrói-se uma família cudemonista, na qual se acentuam as relações de sentimentos entre os membros do grupo: valorizam-se as funções afetivas da familia que se torna o refügio privilegiado das pessoas contra as pressões econômicas e sociais. É o fenômeno social da familia conjugal, ou nuclear ou de procriação, onde o que mais conta, portanto, é a intensidade das relações pessoais de seus membros, como já o dizem Oliveira e Muniz, desde o início da década de 90, entre nós. ${ }^{3}$

O desapego às formulações do passado não quer significar que está melhor ou que está pior, este modelo familiar de agora - embora provavelmente esteja melhor, uma vez que a tendência de alteração procura levar, no mais das vezes, a um reconstruído mais adaptado e suficiente - mas quer significar, certamente, que é preciso prestar grande atenção no que se apresenta de distinto, para que não se dê tratamento anacrônico a nenhuma das experiências vivenciadas pelos membros da família contemporânea, ou a nenhuma das relações humano-jurídicas entre eles desenvolvidas.

Estas mudanças são importantes e devem ser obrigatoriamente observadas e analisadas, uma vez que não vêm do nada, mas decorrem do fenômeno maior de reconstrução do pensar humano, seja pela erosão de valores, pela alteração de parâmetros de comportamento, pela decrepitude e pela inadequação das instituições aos desafios presentes, pelas mudanças sócio-econômicas, pelas crises simultâneas que afetam diversos aspectos da vida organizada em sociedade. pela explosão de complexidade provocada pela emergência de novos conflitos sócio-institucionais, pela re-qualificação dinâmica dos modos de produção, pelas alterações profundas nos modos tradicionais de se conceber o ferramental jurídico para a construção de regras sociais... ${ }^{4}$ Seja como for, a mudança que se propala não veio do nada. Ela se deu de modo contínuo; por isso faz sentido, e muito.

Especificamente no ambiente familiar, como é que tudo isso se espelha e reflete? O que a pós-modernidade promoveu de rupturas, mudanças e avanços, relativamente ao tempo anterior? O que é exatamente esta etapa da vida da civilização humana que se tem denominado pós-modernidade? Como se apresenta a instituição da

OLIVEIRA, J. L. C.; MUNIZ. F. J. F. Direito de familia. Porto Alegre: Sergio Fabris Editor, 1990. p. 11.

4 BITTAR, Eduardo C. B. O Direito na pós-modernidade. Rio de Janeiro: Forense Universitária, 2005. p. 6. 
família, nesse novo tempo. Quais os papéis que desempenham contemporaneamente os seus membros? Do que é que se trata, afinal?

2. Um breve traçado acerca do espírito e da configuração da pós-modernidade

Em Pós-modernismo, razão e religião. Ernest Andre: Gellner, falecido em 1995. se referiu ao pós-modernismo de maneira nada receritiva, marcada pela sua indisposição à face do significado desta concepção de dificílimo alcance. Disse ele que o pós-modernismo é um movimento contemporâneo, que é forte e está na moda. Mas afirmou que, sobretudo, não é completamente claro o que diabo ele é. Siem se dar por satisfeito acerca de sua dura crítica e ferrenha desconfiança, Gellner alfirietou que, na verdade, a claridade não se encontra entre os seus principais atributos, concluindo que o pósmodernismo não apenas falha em praticar a claridade mas en ocasiões até a repudia abertamente..." $\circ$

Compreensível que assim tenha sido a sua visão acerca do termo, tendo em vista sua preferência pelo positivismo e pela segurança que é conferida pelos fútos testáveis, conforme se pode verificar em suas palavras próprias, na mesma importante obra referida, quando diz que positivismo é a crença na existência e disponibilidade de factos objectivos, e sobretudo, na possibilidade de explicar os ditos factos por meio de uma teoria objectiva e testável, ela própria não essencialmente ligada a nenhuma cultura purticular, observador ou estado de espirito. ${ }^{7}$

Pelo viés oposto, o filósofo francês Jean-Françcis Lyotard, falecido em 1998, foi um dos mais importantes pensadores na discussão da vivência de uma pósmodernidade, prestigiando-a - principalmente em sua obra denominada $A$ Condição Pós-Moderna - como verdadeiro rompimento com as antigas verdades absolutas, como marxismo e liberalismo, todas elas legítimas representantes da anterior era, à qual se convencionou denominar modernidade. ${ }^{\mathrm{P}}$

Como um e outro dos pensadores mencionados, as visões antagônicas se multplicaram (e se multiplicam) por todos os lados, refletindo. aliás, aquilo que poderia ser considerado como a essência ou o espirito da modernidade, vale dizer, a preferência pelos pilares inamoviveis das certezas e das verdades, a maior ; Jarte delas tanto seguras quanto constrangedoras, segundo a minha visão pessoal.

s O texto utilizado na composição deste item do presente trabalho foi escrito recentemente pela autora para abrir, como prefácio, a obra coletiva denominada Introdução critica ao código civil, organizada por Lucas Abreu Barrơso, a ser publicada pela Editora Forense, em breve.

- GELLNER, Ernest André. Pós-modernismo, razão e religião. Lisboa: Editora Instituto Piaget, 1994. Id. Ibid.

LYOTARD, Jean-François. A Condição Pós-Moderna. 5. ed. Rio de Janeiro: José Olympio, 1998. 
Não scria razoável, nem justo, nem mesmo consentâneo com os meus aceites e com as minhas visões, se eu não abrisse espaço para registrar que nem tudo, na nova conformação pós-moderna, encontra-se adequadamente resolvido ou encaixado - e nem mesmo poderia estar pois, para estar, esta tarefa teria que ser algo como que divina, ao menos... - o que reflete apenas a conclusão de que o confronto entre os paradigmas da modernidade e os da pós-modernidade são ambíguos às vezes, ou são superpostos outras vezes, ou são simplesmente conflitantes, ou sem registro de pertencerem à mesma classe evolutiva. simplesmente. A pessoa humana de hoje é o individuo de antes, sob o ponto de vista do envólucro, mas seu espaço, sua cena, seu papel. sua significância certamente são muito distintos. entre um e outro modo de se mirar o ser humano propriamente dito. Ĺma consequência curiosa disso - que pode ser uma visão boa ou-não ‥ é o fato de que o homem de hoje parece ter se interiorizado em suas projeções sociais, quer dizer. de um ou de outro modo, a preocupação com a subjetividade faz com que o esquadro da intersubjetividade seja mais apertado que antes.

Como já se deixou assente. antes: isso é bom. ou-não? Significa progresso, avanço e construção sempre, ou não? Só o tempo verdadeiramente dirá, é claro. Ainda assim. prefiro testar. Incomoda-me muito a descoragem e a mesmice das coisas e das atitudes. Além disso, a desconstrução paradigmática em prol da pós-modernidade sempre me sugere a idéia de oxigenar ranços ancestrais, e a idéia me agrada muito, mesmo que possa, eventualmente, deixar a descoberto a ansiada segurança que a era anterior tanto procurou conceber e estruturar. Ainda assim, prefiro testar.

Por isso, e na esfera de minha singular preferência científica e axiologica Direito e justiça - renovo a afirmação de que prefiro o justo ao seguro. Bem por isso, posso dizer que prefiro esta cra que desponta, a pós-modernidade que curiosamente já desponta batizada, ainda que não se saiba exatamentc qual é o marco cronológico deste seu despontar - pelo seu traço mais consentâneo com a contemporaneidade que permite a cada um de nós a chance de descobrir uma outra maneira de ver o mundo, e de se ver no mundo. Um fenômeno assim não acontece de repente, num abrir e fechar de olhos durmo moderno e acordo pós-moderno! - mas é fruto de um razoavelmente lento evoluir de idéias, de concepções, de maneiras de se encarar e interpretar os fatos da vida e das relações humanas. Úm outro modo de visualizar, absorver e compreender o mundo e suas tramas todas, as que já eram tramas desde ontem, as que se descortinam agora e as que estão na imanência de se darem por conhecer. Não um modo ideológico, ou político. ou antropológico, apenas. Mas um modo amplo e entrelaçado, com diversos vieses e muitas arestas, mas sempre um modo distinto do que se teve até então. Por isso. ao mesmo tempo que significa evolução, significa igualmente ruptura, pois a singela 
transformação não teria dado conta de uma (re)evolução assim, não fossem as indispensáveis quebras de grilhões - rupturas paradigmáticas, como se costuma dizer -que tendessem a deixar permanecer engessado e endurecido o anterior modo de se entender os homens, seus múltiplos aspectos, suas inter-relações, a sua sociedade, as suas instituições.

Para o Direito, e conforme entendo, uma ruptura assim, associada a um evoluir assim, produziu uma extraordinária maneira de se enxergar, tratar, estruturar, modelar e maximizar o fenômeno jurídico. A aplicação do Direito não é mais apenas umn ato de conhecimento, conforme expressa Luís Roberto Barroso, ${ }^{9}$ no sentido da revelação de uma norma pré-existente, mas também um ato de vontade, no sentido da escolha de uma possibilidade dentre as diversas que se apresentam. E o que permite que isso aconteça, sem comprometimento desastroso do resultado - em perverso e prejudicial enfoque de justiça aleatoriamente desenhada, evocada e distribuida, como acontece com certas vertentes menos confiáveis do chamado Direito Alternativo - reside no viés constitucionalizado que se transporta hoje para as lindes das relações privadas e do próprio Direito Civil, organizando o que se tem anunciado como Direito Civil constitucional. O mesmoautor citado escreve que o Direito Constitucional define a moldura dentro da qual o intérprete exercerá sua criatividade e seu senso de justiça. sem the conceder, contudo, um mandato para voluntarismos de matizes variados. ${ }^{10}$ Assim é.

E assim é porque o salto qualitativo que a pós-modernidade impôs ao Direito, mormente ao Direito Civil, correu no sentido da sua releitura, do seu reposicionamento espacial e temporal, estruturando-se com isso uma dimensão nova que reaproxima Direito e Ética. Este salto qualitativo demonstra-se, importantemente, no resgate ou revisão de princípios constitucionais que passam a ocupar papel de destaque na seara hermenêutica da aplicação do Direito ao caso concreto. Os princípios passam a conviver com as regras jurídicas, não para abatê-las ou minimizá-las, mas para produzir, em razão do convivio, uma mais significativa aplicação do Direito em prol da justiça, pelo fato da unidade que esta conjugação oferece ao sistema, pelo fato da síntese axiologica que os principios abrigam, e pelo fato de que eles efetivamente passam a condicionar a atividade do intérprete na sua busca da formulação da regra genérica que vai reger a espécie, in casu. Dito por outro modo, os princípios alcançam outra esfera

- BARRUSO. Luis Roberto. Fundamentos teoricos e filosóficos du novo Direito Constitucional brasileiro: pós-mudernidade, teoria crítica e pós-positivismo.In: GRAU, Eros Roberto; CUNHA. Sérgio Sèrvulo da (Coords.). Fstudos de Direito Constitcional em homenagem a José Afonso da Silva. São Paulo: Malheiros Editores, 2003. p. 29.

I" ld. Ibid., p. 29-30. 
valorativa no contexto hermenêutico, pois eles ganham foros de norma jurídica. Não no sentido da regra positiva, simplesmente, mas no sentido do arcabouço maior que ofertam, como mandamentos de otimização que são, na linguagem de Robert Alexy." Diferentemente das regras - o autor expõe - os princípios não têm a estreiteza biunívoca de comprometimento com o substrato fático típico, como o têm as regras, que ou aceitam a subsunção dele ao seu tecido legislado, ou-não o aceitam. Os princípios, diferentemente, abrem os seus horizontes porque pretendem ser realizados amplamente, embora dentro dos naturais limites da possibilidade jurídica existente no caso concreto.

Os princípios são, enfim, a mais alta expressão da normatividade, porque a norma jurídica, como gênero, compreende os princípios e também as regras. As regras vigem e os principios valem, como tão rica e sinteticamente descreve Paulo Bonavides. ${ }^{12} \mathrm{E}$ por assim ser e por assim valer, os princípios re-dimensionados pela visão da pósmodemidade alimentam todo o sistema, não apenas a Constituição propriamente dita, não apenas a lei, mas o Direito em toda a sua extensão, substancialidade, plenitude e abrangência. ${ }^{13}$

Certamente neste espaço se incluem o Direito Civil da contemporaneidade, o Direito de Família da pós-modemidade e os códigos que os regulamentam, que devem, por isso mesmo, ser compreendidos c aplicados conforme tal visão, sob pena de tornarem-se, em tempo brevíssimo, senão uma inútil montanha de papéis, recheada de inúteis regras.

3. O Direito de Família, o Direito das famílias, os direitos familiais: os membros da família contemporânea posam para outra foto sobre a larcira

\subsection{Sobre a lareira, a foto pós-moderna da conjugalidade}

A pós-modernidade traz a novidade da valorização do prazer e o desassocia da noção de dever, fragilizando a fortaleza moralizadora dos séculos precedentes (pelo tanto que mais nos interessa, os séculos XIX e XX). As posturas ilegitimas que foram condenadas pelo moralismo sexual do anterior século como, por exemplo, o excesso de relações e passatempos amorosos. a prática sexual depois dos 50 ou 60 anos, a felação. a masturbação (mormente a recíproca). o direito ao orgasmo, a opção pelo amor livre e a prática homossexual (entre outras formas de afetividade),

1 ALEXY, Robert. Teoria de los derechos fundamentales. Madri: Centro de Derechos Constitucionales, 1993. p. 81 ess.

12 BONAVIDES. Paulo. (urso de Direito constitucional. 17. ed. São Paulo: Malheiros Fditores. 2005. p. 288-289.

13 IJ. Tbid. 
foram paulatinamente perdendo o grande peso pecaminoso e imoral. libertando as pessoas, não para o acesso livre e indiscriminado do prazer, mas para escolherem suas preferências e procurarem, sem essas amarras externas (e cruéis no mais das vezes), realizar os seus projetos pessoais de felicidade.

Não apenas isso, mas a condição matrimonializada foi sempre eternizada, com chance zero de desorganização ou desfazimento, especialmente se em favor da libertação da mulher, uma vez que a sua projeção e atuação no meio familiar estava muito mais voltada à concepção, geração e criação de fillhos do que propriamente o prazer que the pudesse ser proporcionado pela relação sexual e afetiva com o seu partícipe de jornadas. A proclamação da pureza das mulheres, a condenação ao adultério, a proibição do aborto e a recriminação às práticas contraceptivas concorreram no sentido de a elas não ser permitido o que aos homens era, ainda que sob os pudores silenciosos da falsa moral novecentista, como, por exemplo, o desfrute de prazeres efêmeros. A visibilidade do adultério masculino contava. por isso mesmo, com a complacência social e até mesmo religiosa em certos casos, minimizando, em favor dos homens, uma severidade e uma rigidez que sempre estiveram presentes na trajetória de condutas femininas.

Sem lar, não há familia; sem família, não há moral; e, sem moral, não há sociedade nem pátria! proclamou Jules Simon, político e pensador falecido em 1896, e que foi primeiro ministro da França entre os anos de 1876 e 1877. Compreensível que o dissesse, ao seu tempo. Incompreensivel que, em tempos globalizados e redefinidos. ainda se afirme categoricamente, hoje, esta sofismática e excludente conclusão. Não perdeu a família seu carisma, seu papel de refúgio e fortaleza para os anseios primeiros de cada um de seus membros. Não. A família ainda é e sempre será este locus privilegiado. Mas o que já parece não mais persistir é, provavelmente, esta sua tônica de indissolubilidade de vínculos, de obrigatoriedade de realização contínua, a qualquer preço ou custo, de amarras de não-libertação.

Novos hábitos, novas aspirações, novos valores, novos costumes e novas permissões passaram assim a florescer, pela emergência da necessidade de novos e respiráveis ares, uma exigência do tempo proclamado como pós-moderno, enfim. E assim se deu, por exemplo, com a liberdade de expressão e a revalorização do sentimento, produzindo, entre outras coisas, o deslocamento do foco de interesse familiar para a criança (e não para a instituição propriamente dita), bem como a autorização para cada membro buscar a sua própria felicidade e bem-estar, valorizando mais a pessoa cada pessoa -.. que o grupo constituido sob os ares da indestrutividade. Esta inversão 
paradigmática andou no sentido de deitar por terra as proclamações terriveis de outrora, como, por exemplo, a de que a unidade social é a familia e não o individuo. ${ }^{14}$

Ainda assim, não foi exatamente de um dia para o outro que o divórcio, como percurso para o re-encontro de destinos mais promissores, instalou-se no mundo contemporâneo. As pressões de toda a sorte, morais, religiosas, éticas e culturais, empataram durante grande número de décadas, e até hoje, a aceitação plena do rompimento da matrimonialização das relações conjugais. Às mulheres divorciadas se imputou o status da indignidade e aos seus filhos a pecha de filhos sem pai. Idas e vindas de aceitação e de rejeição ao novo modus de desfazimento da sociedade conjugal foram amplamente sentidas e registradas ao longo da modernidade, como que em dança de caranguejos, com passos à frente e com passos atrás. Aliás, até os dias de hoje, em certas antigas e importantes culturas, ainda é assim, quando não se proíbe terminantemente a idéia de desfazimento do laço matrimonial. Paira uma idéia, em certos pensamentos e culturas, de que o rompimento dos laços de conjugalidade corresponderia a uma efetiva perda, e essa sensação é insuportável pelos que se alistam nas colunas dos eternos vencedores. Este dado, de caráter e fundamento psicológico particularizado, não é tão estranho quanto possa parecer à primeira vista, nem é tão raro de ocorrer, como se possa pensar, em tempos de inauguração de um milênio novo e de um novo tempo de registros históricos da trajetória humana. Está próximo de nós, ainda que nos dias da pósmodernidade, inacreditavelmente. ${ }^{15}$

Embora isso, no entanto, tudo indica que caminhamos a passos largos até - para um revisão de concepção e de estrutura, acerca da família e do casamento, muito significativa. Marcos Colares. em feliz observação e síntese, escreveu que deve haver algo de novo no Direito de Familia: a vontade de vencer os limites ridículos da acomodação intelectual. Porérn, tudo será em vão sem a assunção pela sociedade de uma postura responsável em relação à família, transformando o texto da Constituição Federal em litra viva. ${ }^{16}$ Ele tem razão: a familia de hoje tende a ser mais sincera. digamos assim, no sentido de que as hipocrisias e as simulações de antes já não encontram mais lugar em cena, estando este espaço muito mais disponibilizado para os tratos francos e as rupturas consentidas e bem analisadas.

14 Conforme BOURGET, Paul. Un divorce. Paris: Plon-Nourrit, 1944, no prefácio de sua obra, citado pur LIPORVETSKY, Gilles. A sociedade pós-moralisı: o crepúsculo do dever e a élica indolor dos tempos democráticos. Tradução Armando Braio Ara. Barueri (SP): Manole, 2005. p. 19.

15 Assim como não está distante do nosso cotidiano. ainda hoje, aquela situação de pasmo total e concreto de alguém a respeito da dissolução do vinculo matrimonial de outrem, pelo divórcio. F́ comum se ouvir dizer. sob as luzes do espanto: Quem diria! Pariciam nascidos um para o outro! Cuisas de ontem. ainda enterradas nos tempos de hoje...

16 COLARES, Marcos. O que há de novo em Direito de familia? Revista Brasileira de Direito de Familia, Porto Alegre, v. 1, n. 4. p. 39-46, jan.'mar. 2000. 
No enquadramento da família atual, uma gama maior de modelos se apresentam, assumindo ela um desenho plural, aberto, multifacetário e globalizado. servindo como locus privilegiado para o desenvolvimento da personalidade humana, no dizer de Cristiano Chaves Farias. ${ }^{17}$ Ele encaminha suas conclusões para dizer que o atual ambiente da pós-modernidade é o ambiente ideal para a realização espiritual e fisica do ser humano, ou seja, somente se justifica a proteção da família para que se efetive a tutela da própria pessoa humuna. $\dot{E}$, por conseguinte, a família servindo como instrumento para a realização plena da pessoa humana e não mais vislumbrada como simples instituição jurídica e social, voltada para fins patrimoniais e reprodutivos. ${ }^{18}$

\subsection{Sobre a lureira, a foto pós-moderna da parentalidade}

$\mathrm{Na}$ ambiência da parentalidade, o novo desenho das relações e das interrelações igualmente se mostra modificado, registrando-se alterações que parecem indicar que ocorreram "perdas" significativas, para os membros da familia, na tradição, nas normas e nos valores sociais, se o patamar de observação for o do clássico clã familiar. Assim, por exemplo, bem se sabe que na sociedade brasileira colonial, era ao chefe da família que restava incumbido o poder de decidir o grau de instrução, ou a profissão, bem como as escolhas sexuais e afetivas de todos aqueles que a ele se encontravam relacionados, sob dependência familiar. ${ }^{19}$ Neste antigo modelo de família, o lar se compunha de um grande número de pessoas, considerando-se a prole numerosa, os agregados, os aparentados de toda a sorte, e os serviçais, todos se misturando pelo espaço amplo durante todo o tempo, o que impedia a consolidação de maior intimidade ou amizade entre os membros, tornando os relacionamentos muito sérios, rigorosos, rígidos e severos, sem grande manifestação de afetividade ou de cumplicidade. Sem espaço também para as discussões e exposição de pontos de vista, as regras seculares se mantinham com eficiência, e a transmissão dos valores como tradição e obediência se processava sem tumultos, de uma geração para outra, de cima para baixo.

O século XIX, contudo, especialmente na sua segunda metade, testemunhou uma significativa mudança no perfil da família brasileira que, graças a uma série de fatores importantes como, por exemplo, a urbanização das cidades, a chegada da luz elétrica, a introdução de modos e costumes europeus trazidos pela Corte portuguesa, a mesclagem de culturas por força do aumento do ciclo imigratório, adquiriu um retrato

\footnotetext{
17 FARIAS. Cristiano Chaves de. A familia da pós-modernidade: mais que fotografia, possibilidade de convivência. Disponivel em: $<$ http://wwwv.juspodivm.com.br/novo/arquivos/artigos/civil_familia/anfarmilia4.pdf $>$.

18 Id. Ibid.

19 Conf. COSTA, Jurandir Freire. Ordem médica e norma familiar: 3. ed. Rio de Janeiro: Graal. 1989
} 
mais afetivo, diga-se assim, mais voltado à formação de familia a partir da própria e pessoal escolha do par conjugal, o que refletiu na reformulação de papéis do homem e da mulher no cenário doméstico, bem como no mercado de trabalho. Outra passou a ser a dinâmica familiar, ainda que - é necessário que se registre - o jugo da mulher ao homem ainda permanecesse, de certa forma, dentro do lar, mesmo que ela já houvesse conquistado o direito ao trabalho, especialmente as mulheres da classe média, chamada burguesia.

Mas os ares da modernidade já se encontravam em circulação e, após os anos 50 do anterior século. implantou e firmou-se mais e mais o perfil libertário que admitia mais e maiores escolhas dos indivíduos, inclusive dentro de seu ambiente familiar. Nas relações entre pais e filhos, o traço autoritário começa a ceder espaço para as decisões conjuntas e para o trato igualitário. ${ }^{20}$ De lá até este tempo, muita mudança ainda houve, mudança agora mais perceptível aos participantes da cena familiar porque acontecem de maneira cada vez mais veloz, mais célere.

Há, na pós-modernidade, um outro modo de estabelecimento das relações parentais, mormente entre pais e filhos, diferente do modelo anterior, certamente. Os modelos fixos do passado desconstroem-se, admitindo uma reorganização cênica no habitat familiar, no qual vivem os pais, os filhos, os avós, num interessante e diferenciado encontro geracional que, por tudo, é diferente das convivências de gerações de outrora. Giddens, citado no excelente estudo de Maria Lúcia Rocha-Coutinho, ${ }^{21}$ afirma com precisão que nas sociedades anteriores a tradição é o meio de lidar com o tempo e o espaço, inserindo qualquer atividade ou experiência particular na continuidade do passado, presente e futuro, os quais, por sua vez, são estruturados em práticas sociais recorrentes, enquanto que, nas sociedades modernas, as práticas sociais são constantemente examinadas e reformadas à luz das informações recebidas sobre aquelas próprias práticas, alterando, assim, construtivamente, seu caráter.

Um fenômeno interessante de ser anotado é aquele que mostra que os filhos já não saem de seus lares originais tão logo deixem a adolescência, como foi comum no modelo de família imediatamente anterior a esse. Aquela expectativa que corria alegremente, há bem poucas décadas, a favor do momento de se alcançar a maioridade, já não se repete hoje, e os filhos se tornam adultos sem passar para a idade.

20 A própria autora deste estudo, nascida em 1950, conheceu este desprendimento da autoridade paterna quando decidiu. aos dezessete anos, na pequena e interiorana cidade paulista de Säo Carlos, deixar o lar para cursar a Faculdade de Direito do Largo São Francisco (USP), na Capital, com o intuito de seguir profissão que, aos olhos de seu pai, nascido nos primeiros anos do século XX, era "profissão exclusiva para homens"...

21 GUIDDENS, A. The consequences of modernity. Cambridge: Polity Press. 1990, citado pur ROCHACOUTINHO, Maria Lúcia. Transmissão geracional e familia na contemporaneidade. In: BARROS, Myriam Lins de (Org.). Familia e gerações. Rio de Janeiro: Editora FGV, 2006. p. 91-106. 
adulta, como é o interessante dizer de Elza Ramos, ${ }^{22}$ prolongando a coabitação entre gerações por razões que não foram consideradas ou vivenciadas nas sociedades anteriores a esta, como, por exemplo, o prolongamento dos estudos, as dificuldades econômicas, o mercado de trabalho mais fechado. Embora conviventes, os estudos mostram ${ }^{23}$ que na maioria dos casos, pais e filhos convivem bem e os pais reconhecem o direito dos filhos a uma vida pessoal (c mesmo sexual), ainda que em situação de coabitação familiar, circunstância esta que nunca foi admitida no seio familiar há bem poucos anos antes. Mas, o lado positivo desta permanência por mais tempo em casa, apurou um convívio intergeracional diferenciado, pois as gerações (avós, pais e filhos) passam a ter a oportunidade distinta de conviver, estando os mais jovens com a definição de suas faixas etárias para além da infância e da adolescência, o que pode tornar o diálogo bastante mais facilitado, ao menos na maioria dos casos.

Assim, e porque as relações interparentais têm sido moldadas muito mais sobre um patamar igualitário do que sob uma torre de poder, exclusivamente, convivem mais produtivamente os mais velhos e mais jovens, cada um deles tendo muito o que ensinar ao outro reciprocamente, fazendo com que as relações hierárquicas, antes baseadas na obediência cega aos modelos de repetição tradicional, cedam espaço para os novos paradigmas norteadores das relações parentais no seio da família contemporânea. como o afeto, o amor, a cooperação, a mútua proteção e a sadia cumplicidade entre seus membros. E não se trata, por certo, de apenas mais um simples discurso de revisão sociológica, antropológica ou psicológica o que se registra aqui, mas sim de um convite à reflexão, no sentido de se perceber, com clareza, que os modelos legislados de uma sociedade em mutação devem estar atentos para a necessidade de acompanharem estas mudanças, sob pena de se tornarem anacrônicos e inúteis. Os códigos da contemporaneidade devem ser tais. portanto, que sejam não apenas abertos e permeáveis às novas visões, mas que sejam despojados de preconceitos e de ranços próprios do passado, para que contenham regras e normas de efetiva eficácia e ajuste com o reclamo social atual.

RAMOS, Elza. As negociações no espaço doméstico: construir a "boa distância" entre pais e jovens adultos "coabitantes" In: BARROS, Myriam Lins de (Org.). Familia e gerações. Rio de Janeiro: Editora FGV, 2006. p. 39-65.

23 Id. Ibid., p. 42-43. 
Maria Lúcia Rocha-Coutinho diz que a familia deve ser entendida em sua complexidade e discrepância de interesses, necessidades e sentimentos. ${ }^{24} \mathrm{Com}$ isso, a psicóloga quer mostrar que a família se movimenta com o movimento dos tempos, que se altera com a alteração dos costumes. que se modifica com a modificação das pessoas que a constituem, em suas relações inter-pessoais.

A foto da família da pós-modernidade retrata muito além de suas funções simplesmente sociais, econômicas, ideológicas, reprodutivas, religiosas, morais, para retratar também os projetos pessoais de cada um de seus membros, na busca pela sua realização e felicidade, sem perder de vista, contudo, a mesma projeção para o todo familiar. Isso porque a sociedade de hoje é assim. Os homens de hoje estão assim. A vida é esta e as condutas humanas assim são realizadas. E, uma vez que a família está inserida em uma sociedade, ela não pode ficar à parte das alterações sociais, assim como, por outro ângulo, a sociedade não pode ficar alheia às mudanças no meio familiar. ${ }^{25}$

Na visão de Giddens, os relacionamentos familiares contemporâneos quer no nível da conjugalidade. quer no nível da parentalidade - se baseiam na primazia do amor, e suas características principais poderiam ser assim enumeradas: a) são relações que se valorizam por si mesmas e não por condições exteriores da vida social e econômica; b) são relações que primam pelo que podem trazer de bom para cada um dos membros do núcleo familiar envolvidos; c) organizam-se pelo viés reflexivo, no qual a comunicação é aberta e tem base contínua; d) são relações que tendem a se verem mais focadas na intimidade, na cumplicidade e na confiança mútua; e) são relações que transformam a obrigação do contato constante em compromisso ético entre os seus participes.

Enfim, a nova família da contemporaneidade não é melhor nem pior do que os modelos familiares que a antecederam, mas é diferente deles, como se disse inicialmente. Nesta família, us aspectos de positividade são bem vindos e são capazes, quiçá, de deixar se ênfase os aspectos que assim não sejam. porque aqueles são aspectos que dizem respeito mais às trocas. às verdades. à cooperação. à complexidade e, principalmente ao afeto entre seus membros.

Para esta nova família. para esta nova foto sobre u lareira, o pensador do Direito, o legislador e o aplicador das leis, todos devem estar muito atentos à nova e

24 ROCHA-COI'TINHO, Maria Lúcia. Transmissão geracional e familia na contemporaneidade. In: BARROS, Myriam Lins de (Urg.). Familia e geraçōes. Rio de Janeiro: Editora FGV. 2006. p. 97.

25 Id. Ibid. 
urgente maneira de se produzir a sua moldura juridica, para fazê-lo de modo amalgamado ao modo ético de ser e de estar-no-mundo, nesta era de agora.

São Paulo, 19 de março de 2006. 